\title{
Gestão dos resíduos sólidos em Escola do Campo: experiência de educação ambiental na EMCEF de São Gabriel/RS
}

\author{
Solid waste management in Escola do Campo: experience of environmental \\ education at EMCEF of São Gabriel/RS
}

\author{
Fabiana Nunes Barcellos ', André Carlos Cruz Copetti ", Eduardo Pastorio III
}

\begin{abstract}
RESUMO
O presente texto consiste no trabalho final do Curso de Especialização em Educação: Práticas de Ensino Interdisciplinares (EDUINTER) da Universidade Federal do Pampa - Campus São Gabriel/RS. Este artigo tem como objetivo realizar um diagnóstico do conhecimento sobre gestão de resíduos e educação ambiental aos membros da comunidade escolar da EMCEF Baltazar Teixeira da Silveira, localizado no Distrito do Cerro do Ouro - São Gabriel/RS. A instituição possui 55 alunos matriculados, da Educação Infantil (Pré-Escola) ao Ensino Fundamental $\left(1^{\circ}\right.$ ao $9^{\circ}$ ano), e 17 servidores (entre professores e funcionários). A ênfase do estudo refere-se em identificar os principais resíduos produzidos na escola e as formas de descarte realizados pela comunidade escolar, no qual identificou-se que os resíduos orgânicos são colocados na composteira existentes na escola e que os resíduos sólidos possuem dois caminhos: 1- descartados em um buraco e incinerados; e 2 - definido como reciclável, conduzidos para a cidade através do ônibus escolar. A coleta de dados foi realizada a partir da aplicação de um questionário aos professores e alunos. Após este diagnóstico, foram realizadas ações de sensibilização ambiental e apresentação de propostas para a coleta dos resíduos sólidos, destacando a importância da Educação Ambiental e a necessidade da aplicação dos conhecimentos teóricos nas ações diárias escolar e familiar.
\end{abstract}

Palavras-chave: Gestão de Resíduos; Educação Ambiental; Educação do Campo; Escola do Campo.

\section{ABSTRACT}

This text consists of the final work of the Specialization Course in Education: Interdisciplinary Teaching Practices (EDUINTER) of the Federal University of Pampa - São Gabriel Campus / RS. This article aims to make a diagnosis of knowledge about waste management and environmental education to the members of the school community of EMCEF Baltazar Teixeira da Silveira, located in the Cerro do Ouro District - São Gabriel / RS. The institution has 55 students enrolled, from kindergarten (preschool) to elementary school (1st to 9th grade), and 17 servants (including teachers and staff). The emphasis of the study refers to identifying the main waste produced in the school and the forms of disposal carried out by the school community, in which it was identified that the organic waste is placed in the existing compost at the school and that solid waste has two paths: 1- discarded in a hole and incinerated; and 2 - defined as recyclable, driven to the city by school bus. Data collection was performed by applying a questionnaire to teachers and students. After this diagnosis, environmental awareness actions and

'Licenciada em Ciências Biológicas, UNIPAMPA. E-mail: fabiologa_2@hotmail.com. ORCID: https://orcid.org/0000-0001-96781814.

"Doutor em Ciência do Solo, UNIPAMPA. E-mail: copettiufsm@gmail.com. ORCID: https://orcid.org/0000-0001-7871-5127.

I"' Mestre em Geografia, UNIPAMPA. E-mail: eduardopastorio@hotmail.com. ORCID: https://orcid.org/0000-0003-2342-7851. 
proposals for the collection of solid waste were performed, highlighting the importance of Environmental Education and the need for application. theoretical knowledge in daily school and family actions.

Keywords: Waste Management; Environmental Education; Rural Education; Field School.

\section{INTRODUÇÃO}

Nas comunidades rurais, pela ligação direta com o meio ambiente em suas atividades produtivas, espera-se que as práticas ambientais sejam condizentes com o cuidado necessário ao meio e que, historicamente, realizam práticas de descartes e aproveitamento dos resíduos culturalmente enraizadas nos povos do campo, sem avaliar o seu impacto no meio ambiente.

Monteiro et al., 2001, define Resíduo Sólido todo o material sólido ou semi-sólido indesejável ou que necessita ser removido por ter sido considerado inútil por quem o descarta em qualquer recipiente destinado a este ato. Para Bueno (2001), lixo é uma palavra derivada do latim lix ou lixae é tudo que se varre da casa, ou seja, de modo geral tudo o que não presta e se joga fora, como cisco, sujeira, imundície.

Conforme a Lei $n^{\circ} 12.305$, de 2 de agosto de 2010, que institui a Política Nacional de Resíduos Sólidos (PNRS), sendo resíduo sólido definido como:

[...] material, substância, objeto ou bem descartado resultante de atividades humanas em sociedade, a cuja destinação final se procede, se propõe proceder ou se está obrigado a proceder, nos estados sólido ou semi-sólido, bem como gases contidos em recipientes e líquidos cujas particularidades tornem inviável o seu lançamento na rede pública de esgotos ou em corpos d'água, ou exijam para isso soluções técnica ou economicamente inviáveis em face da melhor tecnologia disponível (BRASIL, 2010).

Os resíduos sólidos englobam todos os materiais rejeitados ou descartados nas atividades domésticas, comerciais e de serviços e englobam materiais com características diversas, desde resíduos inertes (entulhos provenientes de obras e demolições), orgânicos provenientes da manipulação de alimentos e poda, embalagens de vidro, plástico, metal, papel/papelão e até resíduos perigosos como embalagens de produtos destinados a eliminação de vetores domésticos, tintas e óleos, bem como aqueles com características de resíduos de serviços de saúde (DIAS, 2002). 
A Associação Brasileira de Normas Técnicas (ABNT) 10.004/2004 conceitua-se como resíduos sólidos:

\begin{abstract}
Resíduos nos estados sólido e semi-sólido, que resultam de atividades de origem industrial, doméstica, hospitalar, comercial, agrícola, de serviços e de varrição. Ficam incluídos nesta definição os lodos provenientes de sistemas de tratamento de água, aqueles gerados em equipamentos e instalações de controle de poluição, bem como determinados líquidos cujas particularidades tornem inviável o seu lançamento na rede pública de esgotos ou corpos de água, ou exijam para isso soluções técnica e economicamente inviáveis em face à melhor tecnologia disponível.
\end{abstract}

Diante desses conceitos, pode-se entender que o uso do termo resíduo seja mais apropriado do que lixo, uma vez que, lixo é algo que não tem mais utilidade, enquanto resíduo, pode ser transformado em outros materiais utilizáveis, como por exemplo, os resíduos orgânicos transformados em compostos orgânicos, os plásticos serem reciclados e assim por diante.

Tecnologias para reaproveitamento da maioria dos resíduos já existe, o grande gargalo está na separação correta, ou seja, nas mãos de quem gera o resíduo, embora temos problema na logística de armazenamento, recolhimento e transporte, pode-se colocar como primordial no sucesso para redução, reutilização ou reciclagem, a educação ambiental, que envolve todos os aspectos ligados ao meio ambiente, não apenas na questão dos resíduos. Um exemplo de que o sucesso está nas mãos do gerador do resíduo é que,o resíduo orgânico não necessita sair do local de origem para ser transformado em substrato, e nem carece de grandes estruturas ou investimentos, e mesmo assim poucos buscam alternativas para tal.

Não é raro ouvir das pessoas que a não separação se deve ao fato de que quando é recolhido, embora separado vão para o mesmo local, aterros. E assim, a cada dia gastamos mais recursos naturais, e desperdiçamos materiais úteis. A verdadeira mudança está na adoção de novos hábitos, e para isso precisamos insistir até as atitudes sejam tão comuns que virem hábitos.

Um dos caminhos é o trabalho com as crianças, que ainda não consolidaram o mau hábito de não cuidar do meio ambiente, mas se nada fizer seguiram os passos dos 
atuais seres humanos. Nesse caminho estão as escolas, locais de concentração desse público e local onde é apresentado e discutido os diferentes conhecimentos e, portanto, local ideal para a formação. O ambiente escolar torna-se o espaço a ser analisado para verificar o quanto os alunos têm o conhecimento e o hábito de separar os resíduos sólidos, de acordo com sua classificação, facilitando coleta para reciclagem e descarte adequado.

\section{OBJETIVO}

A ênfase do estudo refere-se em realizar um diagnóstico do conhecimento sobre gestão de resíduos e educação ambiental aos membros da comunidade escolar da EMCEF Baltazar Teixeira da Silveira. De forma específica: 1 - Identificar os principais resíduos produzidos na escola e as formas de descartes realizados pela comunidade escolar; 2 - Realizar atividades/ações pedagógicas que promova a discussão da Educação Ambiental e Gestão dos Resíduos; e 3 - Sensibilizar a comunidade escolar sobre a importância da Educação Ambiental e a relação com a Educação do Campo.

\section{MATERIAIS E MÉTODOS}

O presente estudo constitui como trabalho final do Curso de Especialização em Educação: Práticas de Ensino Interdisciplinares (EDUINTER) da Universidade Federal do Pampa - Campus São Gabriel/RS. Para a execução deste trabalho, realizou-se os seguintes passos: 1 - Definição do objeto de estudo e seleção do público-alvo; 2 Aplicação de entrevistas semi-estruturadas; 3 - Análise dos dados coletados; 4 Levantamento teórico sobre Gestão de Resíduos, Educação Ambiental e Educação do Campo; 5 - Palestras/Oficinas sobre as temáticas; e 5 - Escrita do artigo final.

O estudo foi realizado na Escola Municipal do Campo de Ensino Fundamental Baltazar Teixeira da Silveira (Figura 1), que encontra-se localizada no Distrito do Cerro do Ouro, a $46 \mathrm{~km}$ da sede administrativa (Figura 2). Consiste em uma Escola do Campo, 
chamada de Escola Polo, atendendo alunos de Educação Infantil (Pré A e Pré B) e Ensino Fundamental - Séries Iniciais e Finais ( $1^{\circ}$ ao $9^{\circ}$ ano), com um total de 55 alunos. Sua criação ocorreu em 08 de novembro de 1993 e, atualmente, realiza suas atividades no período integral e alternado nas segundas, quartas e sextas-feiras.

Figura 1 - EMCEF Baltazar Teixeira da Silveira

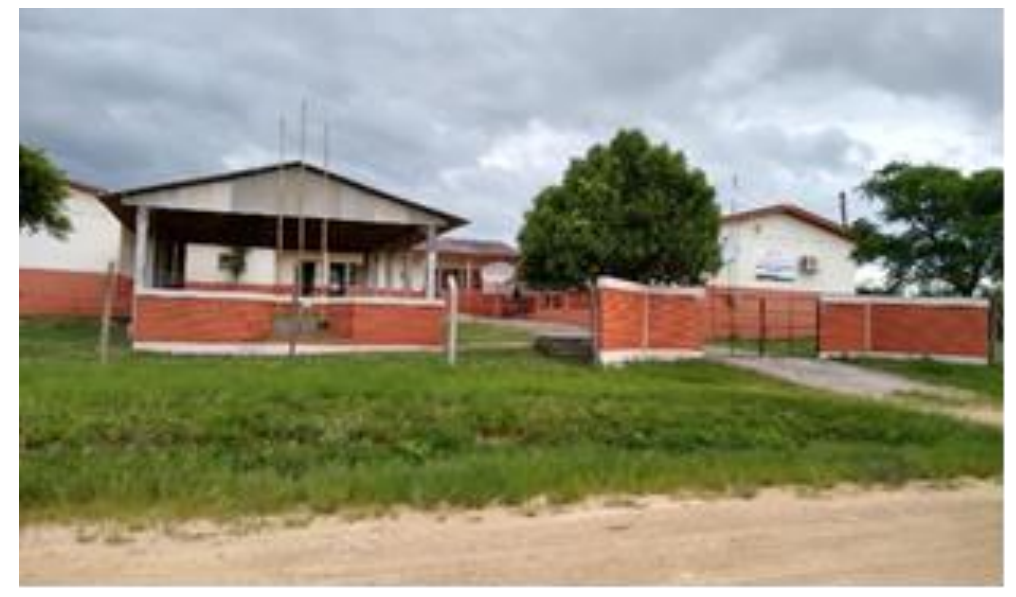

Fonte: Autores, 2019.

Figura 2 - Mapa das Escolas Municipais do Campo de São Gabriel

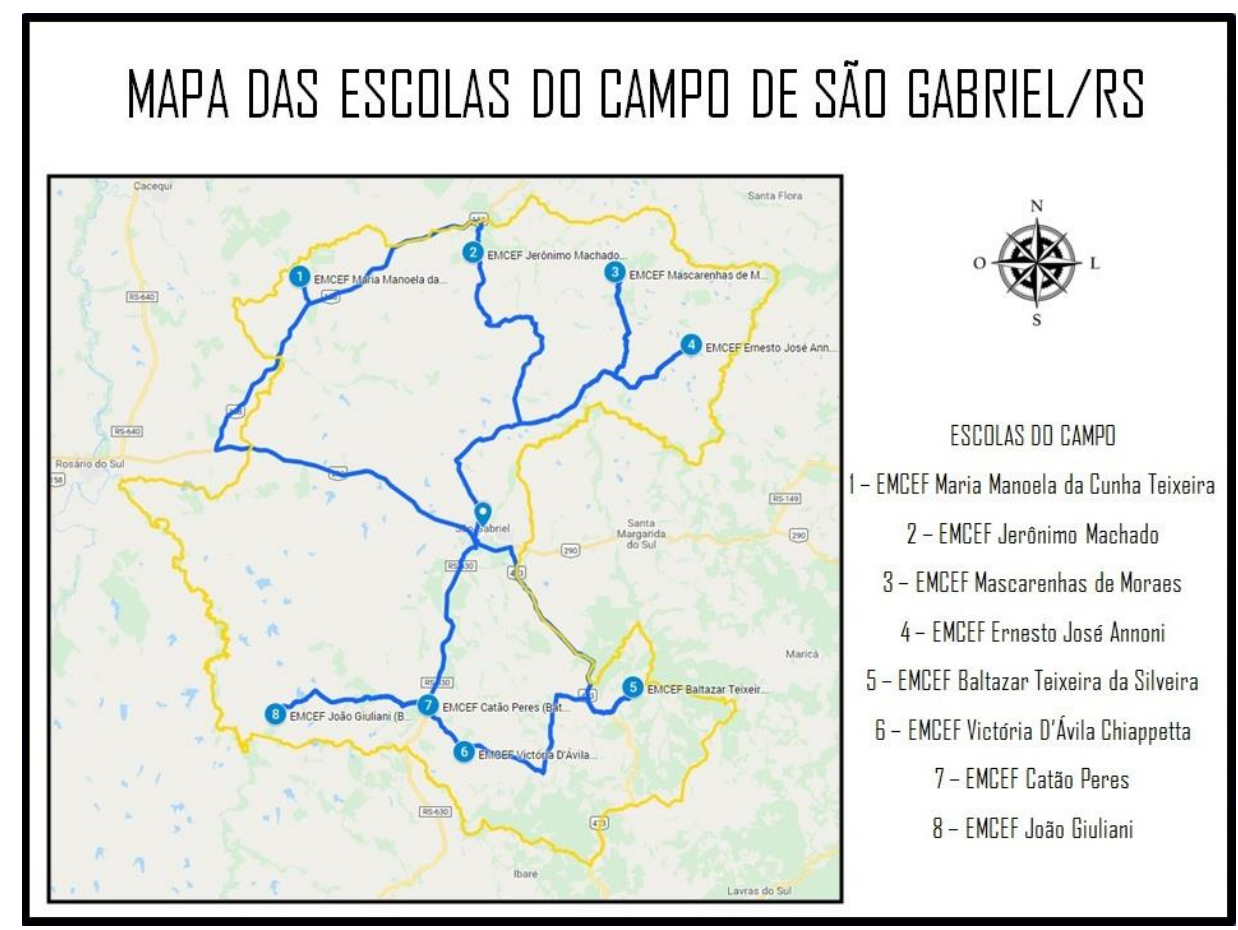

Fonte: Pastorio, 2018. 
Para atender os objetivos, baseou-se na análise de um questionário respondido por alunos do ensino fundamental, do $4^{\circ}$ ano ao $9^{\circ}$ ano, e pelo corpo docente $e$ funcionários da escola, com perguntas relacionadas sobre a produção de resíduos. Em que foi classificado qualitativamente em: 1 . Resíduo sólido seco reciclável; 2 . Resíduo sólido seco não reciclável; 3. Resíduo sólido orgânico; 4. Resíduo eletrônico; e, Quais os destinos dados para cada classe.

Após a análise dos resultados obtidos nos questionários foi realizado uma atividade com a apresentação do documentário "História das Coisas", para apresentar da origem até o descarte dos produtos. Após, foi realizado uma oficina pelos alunos, para confecção de cartazes que foram colocados na escola e auxiliar na correta separação dos resíduos sólidos produzidos na escola.

Nessa escola existem coletores de lixo para cada tipo de resíduo sólido produzido na escola, sendo eles: amarelo (metal), plástico (vermelho), vidros (verde) e o lixo orgânico é colocado na compostagem para que vire adubo e utilizado na horta. Existe separação seletiva na escola, porém sabe-se que a maioria dos resíduos sólidos gerados são incinerados ou levados pelo transporte escolar para a cidade. Destaca-se ainda que no município de São Gabriel não possui coleta de lixo no meio rural.

Figura 3 - Lixeiras Seletivas na EMCEF Baltazar Teixeira da Silveira

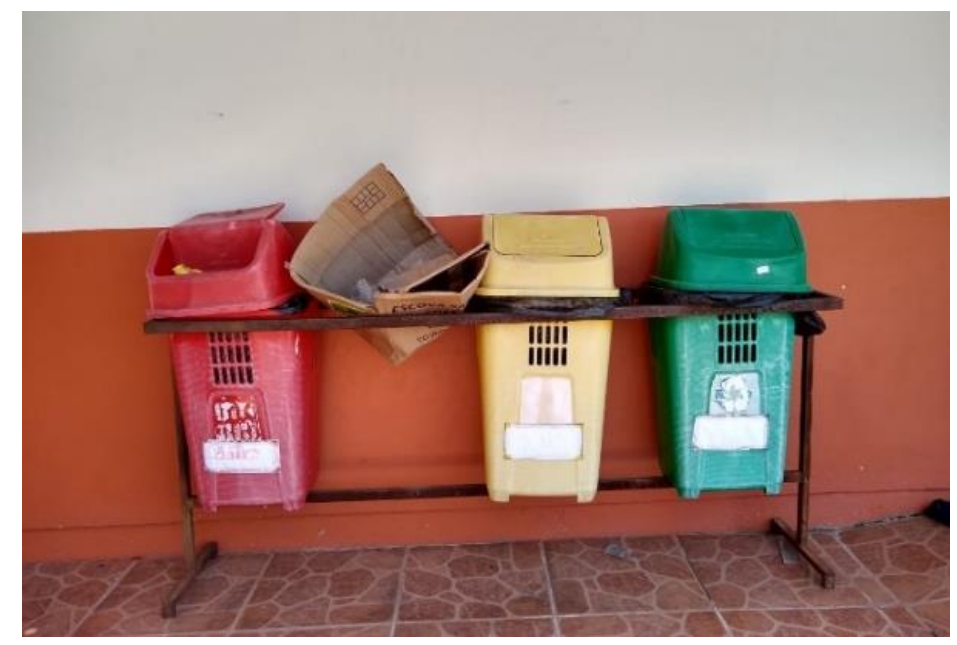

Fonte: Autores, 2019. 


\section{RESULTADO E DISCUSSÃO}

\subsection{Educação do Campo e Educação Ambiental}

Como o estudo consiste em uma Escola do Campo, torna-se necessário pensar o conceito de Educação do Campo, como instrumento de análise e como forma de materializar as discussões de Educação Ambiental e Gestão de Resíduos, no contexto pedagógico da escola e no ambiente social e cultural da comunidade escolar.

A Educação do Campo é considerado recente no contexto teórico brasileiro, datadas do final do século XX. Para sua análise é importante compreender que suas premissas vêm sendo fixadas pelas políticas educacionais, que garantem o seu direito e que permite pensar o fazer pedagógico no contexto escolar.

Em termos legais, avança com a aprovação da Lei $N^{\circ}$ 9394/96, de 20 de dezembro de 1996, que estabelece a Lei de Diretrizes e Bases da Educação Nacional (LDB), que destaca em seu Artigo 28, que

$\mathrm{Na}$ oferta de educação básica para a população rural, os sistemas de ensino promoverão as adaptações necessárias à sua adequação às peculiaridades da vida rural e de cada região, especialmente:

1. conteúdos curriculares e metodologias apropriadas às reais necessidades e interesses dos alunos da zona rural;

2. organização escolar própria, incluindo adequação do calendário escolar às fases do ciclo agrícola e às condições climáticas;

3. adequação à natureza do trabalho na zona rural. (BRASIL, 1996).

Depois da LDB, temos a aprovação da Resolução CNE/CEB N¹, de 3 de abril de 2002, que institui as Diretrizes Operacionais para a Educação Básica nas Escolas do Campo, que em seu Artigo 5, o texto menciona que,

As propostas pedagógicas das escolas do campo, respeitadas as diferenças e o direito à igualdade e cumprindo imediata e plenamente o estabelecido nos artigos 23,26 e 28 da Lei 9.394, de 1996, contemplarão a diversidade do campo em todos os seus aspectos: sociais, culturais, políticos, econômicos, de gênero, geração e etnia. (BRASIL, 2002).

A próxima legislação é um marco para a Educação Básica, pois institui a Educação do Campo como modalidade de ensino, devendo ser trabalhada nos diferentes níveis da 
educação brasileira, através da Resolução $N^{\circ} 4$, de 13 de julho de 2010, que define as Diretrizes Curriculares Nacionais Gerais para a Educação Básica.

Por fim, temos o Decreto $N^{\circ} 7352$, de 04 de novembro de 2010, que Dispõe sobre a política de educação do campo e o Programa Nacional de Educação na Reforma Agrária - PRONERA, que em seu Art. $1^{\circ}$, parágrafo $\S 1^{\circ}$, destaca:

I - populações do campo: os agricultores familiares, os extrativistas, os pescadores artesanais, os ribeirinhos, os assentados e acampados da reforma agrária, os trabalhadores assalariados rurais, os quilombolas, os caiçaras, os povos da floresta, os caboclos e outros que produzam suas condições materiais de existência a partir do trabalho no meio rural; e

II - escola do campo: aquela situada em área rural, conforme definida pela Fundação Instituto Brasileiro de Geografia e Estatística - IBGE, ou aquela situada em área urbana, desde que atenda predominantemente a populações do campo.

Já em seu Artigo $2^{\circ}$, define os princípios da Educação do Campo, sempre com preceitos de valorização dos povos do campo, respeitando suas diferenças culturais, sociais, religiosas, ambientais, políticas, ambientais, econômicas, étnicas, geracionais, de gênero, de raça e demais diversidades do campo, sempre buscando a identidade da escola do campo, através de projetos pedagógicos e currículo adaptado, adequado a realidade dos povos do campo.

Para corroborar, podemos citar a Base Nacional Comum Curricular (2014) e o Referencial Curricular Gaúcho (2018), criados para pensar o currículo das instituições de ensino da educação Básica e manifesta-se que a Escola do Campo,

Determina aprendizagens essenciais para a formação do estudante por meio de competências e habilidades, entres elas, a valorização da diversidade de saberes e vivências culturais. Nesse caso, a escola localizada no meio rural possui uma especificidade própria, congrega uma cultura diversa de saberes que possibilita a elaboração de uma proposta pedagógica diferenciada que reflete sua realidade no currículo escolar.

Desta forma, desenvolver a Educação do Campo que consiste em respeitar as vivências dos alunos, o contexto da Educação Ambiental (EA) e Gestão de Resíduos é parte integrante deste processo. Além disso, já existe um entendimento que as políticas públicas para a Educação Ambiental devem ser pensadas a partir de ações coletivas e 
transformadoras, que contribua na prevenção e enfrentamento dos problemas ambientais locais, regionais e globais.

O marco inicial da Educação Ambiental no ensino formal no Brasil ocorreu pela Lei $n^{\circ}$ 6.938/81, que instituiu a Política Nacional de Meio Ambiente, estabelecendo a EA em todos os níveis do ensino. Como continuidade, temos a Política Nacional de Educação Ambiental (PNEA), instituída pela Lei $n^{\circ}$ 9.795/99, mas regulamentada em decreto de 2002, que acelerou o processo da institucionalização da Educação Ambiental.

Percebe-se que o caminhar das políticas de Educação do Campo e de Educação Ambiental ocorreram no mesmo período, sendo que não estavam instituídas enquanto políticas públicas próprias. A partir do advento da LDB n9394/1996, as particularidades existentes no Brasil receberam atenção e começaram a ser pensadas como conceitos individuais.

Ambos conceitos foram criados para o ensino formal, no ambiente escolar. Ações que buscam refletir seus significados e sua aplicação nas escolas, tornam-se pertinentes para a materialização enquanto política pública.

\subsection{Diagnóstico do conhecimento sobre a gestão de resíduos e ambiental na escola}

Para a realização de um diagnóstico sobre a Gestão de Resíduos e Educação Ambiental foi realizado a aplicação de um questionário para os professores, funcionários e alunos sobre a produção e descarte dos resíduos na escola.

Assim, foram distribuídos 17 questionários entre os professores e funcionários, sendo que 15 questionários foram respondidos. Na Tabela 1 apresenta-se as perguntas aplicadas nos questionários e as respectivas respostas encontradas. 
Tabela 1 - Perguntas e respostas dos questionários aplicados aos professores e funcionários sobre a produção e descarte dos resíduos na escola

\section{Perguntas}

1 Tipos de resíduos gerados na escola

2. Destinos desses resíduos

3. Existe coleta seletiva na escola

4. Sabe quem é responsável pelo descarte dos resíduos

5. Se você descarte corretamente os resíduos na escola

6. Se realiza a separação dos resíduos na sua residência, como

7. Se houvesse coleta, você separaria seu resíduo de outra forma

8. Sugestão para resolver os problemas do descarte dos resíduos

9. Classe dos resíduos

\section{Respostas}

Orgânicos (8); secos (8); não reciclado (1); e, todos (7).

Queimada (7); composteira (3) e levados pra São Gabriel pelo ônibus escolar (9); não sabem (3); e, separados (2).

Sim; e, os resíduos são separados.

Funcionários/faxina (5); supervisora / direção (3); não sabem (6); e, sim (1).

Sim; e, em partes.

Sim; seco do orgânico; e, não reciclável.

Sim.

Realizar palestras de conscientização para comunidade; ter pontos de coleta; e, um caminhão de recolhimento.

1. resíduos sólidos seco reciclável;

2. resíduo sólido seco não reciclável;

3. resíduo sólido orgânico;

4. resíduo eletrônico.

Fonte: Autores, 2019.

Segue abaixo gráficos (Gráfico 4,5 e 6) que representa um fragmento das respostas às perguntas presente na aplicação do questionário aos alunos (40 - $9^{\circ}$ ano). 
Gráfico 1 - Respostas dos Alunos à Pergunta 1 do Questionário (Tipos de resíduos gerados na escola)

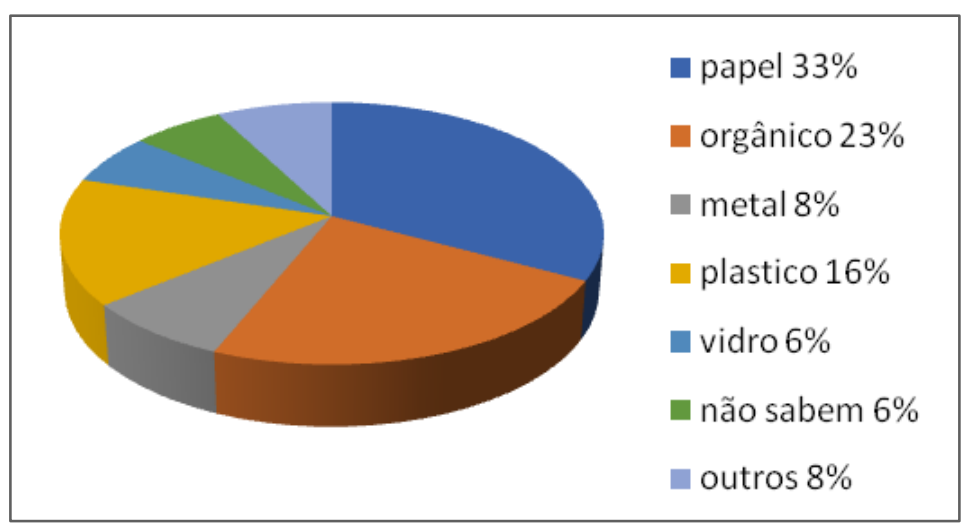

Fonte: Autores, 2019.

Gráfico 2 - Respostas dos Alunos à Pergunta 2 do Questionário (Destinos destes resíduos

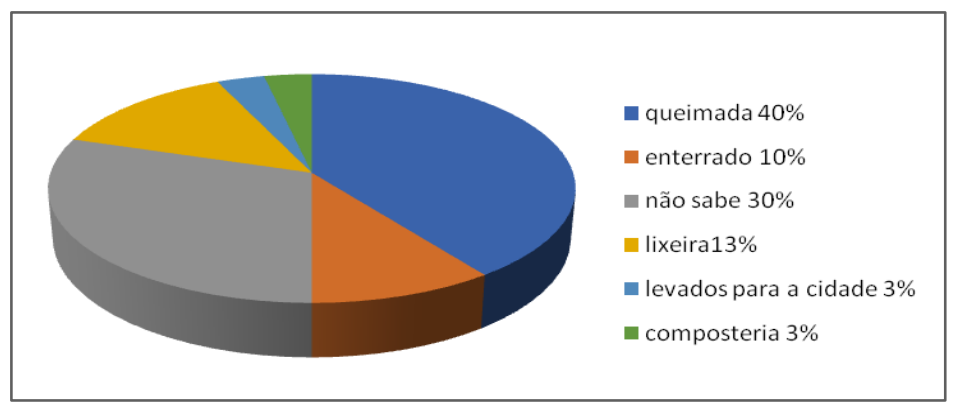

Fonte: Autores, 2019.

Gráfico 3 - Respostas dos Alunos à Pergunta 4 do Questionário (Se sabem quem é o responsável pelo descarte dos resíduos)

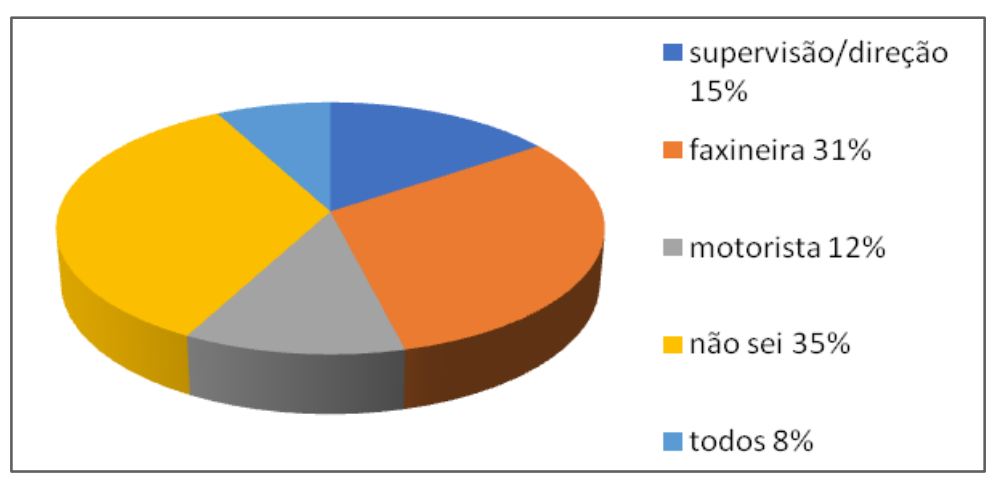

Fonte: Autores, 2019. 
Com a análise das respostas dos professores e funcionários e alunos, foi constado que suas respostas estão restritas. Segundo Pinhão \& Martins (2012), cada vez mais, são motivados desenvolvimentos de ações escolares que levem em conta a relação dos temas ambientais com a qualidade de vida do homem e do planeta. $\mathrm{O}$ aluno deve ser preparado para tomar decisões conscientes que impliquem até mesmo no rompimento de hábitos nocivos, mas socialmente aceitos e estimulados pelos meios de comunicação.

O processo participativo, onde o indivíduo atua no diagnóstico de problemas ambientais e na busca de possíveis soluções e concretização de ações, torna-o um agente transformador, desenvolvendo habilidades, atitudes e conduta ética no exercício da cidadania (MORAES, 2004). Portanto, a relação Homem e Natureza pressupõem uma nova visão e a convivência do Homem com as demais espécies do planeta permite a percepção, a compreensão e a participação dele perante o meio ambiente.

A partir da análise dos questionários respondidos por professores, funcionários e alunos, nota se diferenças nas respostas, um exemplo na pergunta 1 os professores foram mais sucintos não exemplificando os tipos de resíduos, mas classificando. Os alunos já exemplificaram, falando dos materiais produzidos na escola.

Na pergunta referente ao descarte dos resíduos, todos falam dos mesmos destinos só que em porcentagem diferentes, mas a maioria relaciona que são queimados, já outros, identificam que os resíduos são levados para a cidade e descartados lá, provavelmente são alunos que utilizam o ônibus que vai até a cidade e observa que acontece este descarte. Entretanto, grande parte dos resíduos sólidos gerados não possui destinação adequada e são descartados incorretamente no meio ambiente comprometendo a qualidade do solo, da água e do ar, por serem fontes de compostos orgânicos voláteis, pesticidas, solventes e metais pesados, entre outros (GOUVEIA, 2012). O manejo adequado dos resíduos é uma importante estratégia de preservação do meio ambiente, assim como de promoção e proteção à saúde. 
Referente aos responsáveis pelo descarte, quase todos refere-se a supervisores, funcionários, motoristas. O interessante em duas respostas dos alunos, relacionou que todos devem ser responsáveis pelo descarte dos resíduos.

A escola possui em todas as salas de aulas lixeiras para o correto descarte, e este ano estamos com um programa da horta escolar, assim, os alunos destinam os resíduos orgânicos na composteira que a escola possui. Não existe muitas ações referente ao descarte correto dos resíduos, na maioria das vezes este assunto só e tratado pelos professores de Ciências. Devemos conscientizar mais os professores para que trabalhem este assunto durante o decorrer do ano letivo, em todas as áreas do conhecimento, este assunto é interdisciplinar, abrangendo todos os assuntos.

Uma das ações realizadas com os alunos do $8^{\circ}-9^{\circ}$ ano, em uma oficina logo após assistirem o documentário e a classificação dos resíduos sólidos, que foi confeccionado um cartaz que foi colocado com as lixeiras existentes Figura 4.

\section{Figura 4 - Alunas do $9^{\circ}$ com Cartaz da Separação Correta dos Resíduos Sólidos}

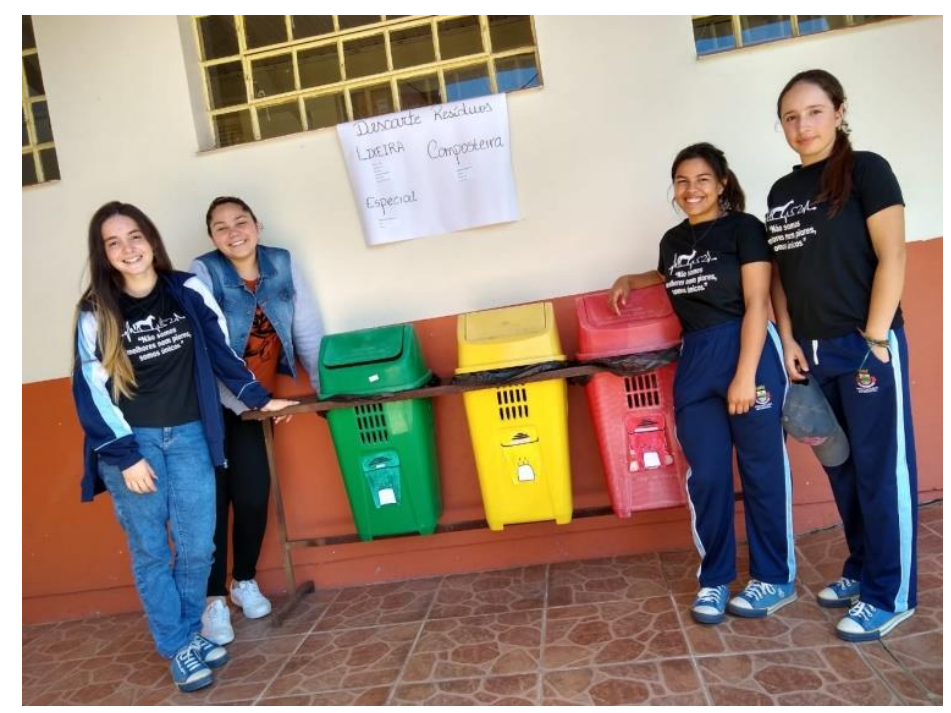

Fonte: Autora, 2019.

Em relação a exibição do documentário "A história das coisas", realizamos uma roda de conversa para conscientizarmos de onde vem e para onde vai tudo o que consumimos. 


\section{CONCLUSÕES}

No nosso ecossistema, diariamente, nos deparamos com problemas ambientais causados pela própria sociedade $e$, isso se relaciona com o consumo acelerado, 0 desleixo da sociedade para com o meio ambiente, o descarte incorreto dos resíduos e demais fatores.

Considerando todo o trabalho de pesquisa realizado na escola, foi levando alguns problemas sobre o assunto, os alunos sabem quais são os resíduos produzidos na escola, mas na prática, não ocorre a separação e destinação correta, pois, um dos grandes problemas da comunidade rural é que não possuem coleta do lixo, assim, a comunidade para não acumular, queima, causando muitos danos a natureza do local

\section{CONSIDERAÇÕES FINAIS}

A análise de dados e a discussão dos resultados dos questionários propiciaram a elaboração de dois produtos: um folder educativo sobre a temática direcionado aos alunos da unidade escolar e um manual sobre a temática direcionado aos professores.

Através da análise dos questionários verificou-se que a comunidade escolar sabe do problema que é queimar os resíduos sólidos, mas como não tem coleta seletiva, este é um dos destinos encontrados.

Uma das propostas de toda a comunidade escolar seria que pelo menos uma vez por semana ou a cada 15 dias viessem recolher os resíduos produzidos na escola e na comunidade, sendo colocados coletores para os mesmos.

Que Educação Ambiental seja abordada com mais ênfase, não só no componente curricular de Ciências da Natureza, mas ser abordada interdisciplinar em todos os componentes do ensino básico, realizando atividades durante todo o ano letivo com os alunos e juntamente com a comunidade escolar, realizando projetos. 


\section{AGRADECIMENTOS}

Agradeço aos meus orientadores por me ajudarem a construção do artigo.

Agradeço aos professores, funcionários e alunos da EMCEF Baltazar Teixeira da Silveira pela disponibilidade de responderem o questionário e realizarem as atividades.

\section{REFERÊNCIAS}

ASSOACIAÇÃO BRASILEIRA DE NORMAS TÉCNICAS. NBR 10.004. Resíduos Sólidos: Classificação. 2. Ed. Rio de Janeiro, 2004.

BRASIL. Base Nacional Comum Curricular. Brasília: MEC, 2017.

BRASIL. Diretrizes Curriculares Nacionais Gerais para a Educação Básica. Resolução CNE/CEB n 4 de 13 de julho de 2010. Ministérios da Educação. Brasília: MEC, 2010.

BRASIL. Diretrizes Operacionais para a Educação Básica nas Escolas do Campo. Resolução CNE/CEB no 1 de 03 de abril de 2002. Ministério da Educação. Secretaria de Educação Continuada, Alfabetização e Diversidade (SECAD). Brasília: MEC, 2002.

BRASIL. Dispõe sobre a política de educação do campo e o Programa Nacional de Educação na Reforma Agrária (PRONERA). Decreto n 7.352, de 4 de novembro de 2010. Brasília: MEC, 2010.

BRASIL. Lei de Diretrizes e Bases (LDB). Lei no 9.394/96. Brasília: MEC, 1996.

BRASIL. Lei n 12.305, de 2 de agosto de 2010. Institui a Política Nacional de Resíduos Sólidos e dá outras providências. Brasília, 2010.

BRASIL. Ministério da Educação. Governo Federal. Base Nacional Curricular Comum, acessado em 25/11/2019.

BRASIL. Política Nacional de Educação Ambiental. Lei no 9.795/99. Brasília: MMA, 1999.

BRASIL. Política Nacional do Meio Ambiente. Lei nº 6.938/81. Brasília: MMA, 1981.

BUENO, S. Minidicionário da Língua Portuguesa. Ed. rev. e atual. São Paulo, 2001.

Decreto Executivo nº 057 de 28 de agosto de 2018, São Gabriel- RS 
DIAS, M. F. S. Caracterização física dos resíduos sólidos urbanos: uma etapa preliminar no gerenciamento do lixo. XVIII Congresso Internacional de Inginiéria Sanitaria y Ambiental. Cancún, México, 2002.

GOUVEIA, Nelson. Resíduos sólidos urbanos: impactos socioambientais e perspectiva de manejo sustentável com inclusão social. Ciênc. saúde coletiva, Rio de Janeiro, v. 17, n. 6, jun. 2012. Disponível em. Acesso em 03 de julho de 2015.

KOLLING, Edgar Jorge, MOLINA, Mônica Castagna (Orgs.) Por uma Educação Básica do Campo: memória. Brasília: Editora Universidade de Brasília, 1999. (Coleção por uma Educação Básica do Campo, nº1).

MONTEIRO, José H. P. et al. Manual Integrado de Gerenciamento de Resíduos Sólidos. Rio de Janeiro. IBAM, 2001.

MORAES, M.C Pensamento Eco-sistêmico: educação aprendizagem e cidadania no século XXI. Petrópolis: Vozes, 2004, 342 p.

PASTORIO, Eduardo. A Educação do Campo na Secretaria Municipal de Educação: o caso do município de São Gabriel/RS (Especialização em Gestão Educacional) - Universidade Federal de Santa Maria, 2018.

PINHÃO, Francine; MARTINS, Isabel. Diferentes abordagens sobre o tema saúde e ambiente: desafios para o ensino de ciências. Ciênc. educ. (Bauru), Bauru, v. 18, n. 4, 2012. Disponível em: https://mc04.manuscriptcentral.com/ciedu-scielo acesso em 03 de julho de 2015.

RIO GRANDE DO SUL. Referencial Curricular Gaúcho. Porto Alegre: CEED, 2018. 